\title{
AVALIAÇÃo DO CULTIVO DE Pleurotus sajor-caju (Fries) Sing. SOBRE O RESÍDUO DE ALGODÃO DA INDUSTRIA TEXTIL PARA A PRODUÇÃO DE COGUMELOS E PARA ALIMENTAÇÃO ANIMAL ${ }^{1}$
}

\author{
Evaluation of the cultivation of Pleurotus sajor-caju (fries) sing. on cotton textile \\ mill waste for mushroom production and animal feeding
}

\author{
Clenderson Corradi de Mattos Gonçalves², Paulo César de Aguiar Paiva ${ }^{3}$, Eustáquio Souza Dias ${ }^{4}$, \\ Félix Gonçalves de Siqueira ${ }^{5}$, Fábio Henrique ${ }^{6}$
}

\begin{abstract}
RESUMO
O resíduo proveniente do beneficiamento do algodão em lixadeiras na indústria têxtil é um material rico em lignocelulose, tem baixa digestibilidade e é pobre em proteínas e minerais, o que dificulta seu uso 'in natura' na alimentação de ruminantes. Neste tarbalho, objetivou-se avaliar a produtividade e eficiência biológica deste resíduo de algodão na produção do cogumelo comestível Pleurotus sajor-caju e avaliar as alterações promovidas no resíduo para alimentação de ruminantes. Foram realizados 5 tratamentos: $\mathrm{T}_{1}-80 \%$ de serragem de eucalipto $+20 \%$ de farelo de trigo (testemunha) $; \mathrm{T}_{2}-50 \%$ de resíduo de algodão $+50 \%$ de serragem; $\mathrm{T}_{3}-45 \%$ de resíduo $+45 \%$ serragem $+10 \%$ de farelo $; \mathrm{T}_{4}-40 \%$ de resíduo $+40 \%$ serragem $+20 \%$ de farelo e $\mathrm{T}_{5}-80 \%$ de resíduo $+20 \%$ de farelo. $\mathrm{O} \mathrm{T}_{5}$ apresentou os melhores resultados para produtividade $(22,46 \%)$ e eficiência biológica $(71,48 \%)$ do Pleurotus sajor-caju. $\mathrm{O}$ fungo alterou a constituição dos substratos nos estágios de produção do cogumelo, principalmente os constituintes da fibra e agregou N ao substrato. Dessa forma, o uso do resíduo de lixadeira de algodão no cultivo de Pleurotus sajor-caju pode se tornar uma alternativa viável para produção de cogumelo e melhorar a qualidade deste resíduo para alimentação animal.
\end{abstract}

Termos para indexação: Pleurotus, Cogumelo comestível, resíduos, substratos, celulose, lignina.

\begin{abstract}
The waste coming from cotton processing in mills in the textile industry is a lignocellulose-rich material, but has low digestibility, and is poor in proteins and minerals, making it inappropriate for ruminant feeding. This study was intended to evaluate the productivity and biologic efficiency of cotton textile mill waste in the production of the edible mushroom Pleurotus sajor-caju, and to evaluate the alterations brought about in the waste for use in ruminant feeding. Five treatments were undertaken in the following manner: T1- $80 \%$ eucalyptus sawdust $+20 \%$ wheat bran (control); $\mathrm{T}_{2}-50 \%$ waste $+50 \%$ sawdust; $\mathrm{T}_{3}-45 \%$ waste $+45 \%$ sawdust $+10 \%$ wheat bran; $\mathrm{T}_{4}-40 \%$ waste $+40 \%$ sawdust $+20 \%$ wheat bran and $\mathrm{T}_{5}-80 \%$ waste $+20 \%$ wheat bran. T5 showed the best results for productivity (22.46\%) and biologic efficiency (71.48\%). Fungus altered the constitution of the substrates in the stages of production of the mushroom. Therefore, the use of cotton textile mill waste in the cultivation of Pleurotus sajor-caju may become a viable alternative for mushroom production, and also improve the quality of this waste for use in animal feeding.
\end{abstract}

Index terms: Pleurotus, Edible mushroom, waste, substrates, cellulose, lignin.

(Recebido em 29 maio de 2007 e aprovado em 14 de julho de 2008)

\section{INTRODUÇÃO}

A cadeia produtiva do algodão gera vários subprodutos desde a limpeza inicial onde se retira o caroço, um subproduto nobre, que é destinado à produção de óleo para alimentação humana ou utilizado in natura na alimentação animal, até a produção dos tecidos, onde surgem subprodutos como o resíduo de lixadeira que são resíduos mais pobres da fibra de algodão.
O resíduo de lixadeira, resultante do beneficiamento da indústria têxtil do algodão, é um subproduto fibroso, tem baixa digestibilidade e é pobre em proteínas e minerais (Santos et al., 2004). Outro problema no aproveitamento direto do resíduo de lixadeira do algodão na alimentação de ruminantes está relacionado com a estrutura da celulose que se apresenta na forma cristalina, e que se caracteriza por apresentar-se altamente organizada e complexa. Esse fator, além de dificultar sua utilização como fonte energética

\footnotetext{
${ }^{1}$ Projeto financiado pelo CNPq.

2Unidade Regional EPAMIG sul de Minas, Campus da UFLA - clenderson@epamig.ufla.br

${ }^{3}$ Universidade Federal de Lavras/UFLA - Departamento Zootecnia/DZO - Lavras, MG

${ }^{4}$ Universidade Federal de Lavras/UFLA - Departamento de Biologia/DBI - Lavras, MG

${ }^{5} \mathrm{MSc}$ em Microbiologia - Formosa, GO

${ }^{6}$ Universidade Federal de Lavras/UFLA - Departamento Zootecnia/DZO - Lavras, MG
} 
para ruminantes, limita sua decomposição no ambiente, gerando problemas ambientais e econômicos para a indústria têxtil (Almeida et al., 2002; Castro et al., 2004).

Uma alternativa para melhorar a qualidade desse subproduto seria o uso de tratamento biológico com a inoculação de basidiomicetos decompositores capazes de degradar celulose, hemicelulose e lignina (Capelari, 1996; Souza, 1998), dentre os quais destacam-se os cogumelos Pleurotus spp. (Mandeel et al., 2005). No Brasil, um dos resíduos mais utilizados no cultivo desses cogumelos é o bagaço de cana-de-açúcar, porém, segundo Dias et al. (2003), há a necessidade de se testar outros substratos, pois o bagaço de cana não é disponível em abundância em todas as regiões, limitando a sua utilização. Nesse contexto, a utilização de resíduos agroindustriais que constituem um problema ambiental e, consequentemente, para as indústrias produtoras, é uma estratégia muito interessante, porque associa a redução de custos do cultivo do cogumelo com uma destinação ecologicamente correta do resíduo.

Além da utilização direta do resíduo para o cultivo de cogumelos, tem-se, ao final do processo de cultivo, um rico substrato que pode ser utilizado como adubo orgânico ou na alimentação animal. Alguns autores estudaram as alterações promovidas por espécies de Pleurotus. sobre diferentes substratos e observaram alterações na constituição da fibra e incremento de nitrogênio, aumentando o valor nutritivo e digestibilidade do substrato, tornando-o apropriado para a alimentação de ruminantes (Bisaria et al., 1997; Adamovic et al., 1998; Schmidt et al., 2003).

Considerando que o resíduo de algodão constitui um problema para a indústria têxtil e que o mesmo é pouco nutritivo para ser utilizado diretamente na alimentação animal, este trabalho foi realizado com o objetivo de avaliar o uso deste resíduo como substrato para a produção do cogumelo Pleurotus sajor-caju e avaliar as alterações promovidas pelo fungo sobre o substrato de cultivo, visando a sua utilização na alimentação de ruminantes.

\section{MATERIAL E MÉTODOS}

Neste experimento foi utilizado um isolado de Pleurotus sajor-caju, cedido pelo Laboratório de Cogumelos Comestíveis do Departamento de Biologia da UFLA - Universidade Federal de Lavras.

A preparação do inoculante foi feita utilizando arroz em casca $(9,0 \mathrm{~kg})$ pré-cozido, por aproximadamente 30 minutos, em água fervente. Após o pré-cozimento, o arroz em casca foi deixado em descanso para escorrer o excesso de água, sendo adicionado logo em seguida: farelo de trigo (1 kg), gesso (200 g), calcário (200 g) e água (1 L). Para o preparo da matriz secundária, a mistura foi acondicionada em frascos de vidro (400 g/frasco), os quais foram autoclavados a $121^{\circ} \mathrm{C}$ por 2 horas, duas vezes. Após o resfriamento, as misturas foram inoculados com o micélio do fungo cultivado em BDA. Para a produção final do inoculante, a mesma mistura descrita anteriormente foi acondicionada em sacos de polipropileno (1 kg/saco) e autoclavados como descrito anteriormente. Após o resfriamento, cada saco foi inoculado com aproximadamente $10 \mathrm{~g}$ da matriz secundária. $\mathrm{O}$ período de incubação foi de aproximadamente 30 dias com temperaturas entre 20 a $28^{\circ} \mathrm{C}$ na casa de colonização.

Foi utilizado como matéria-prima lignocelulósica nos tratamentos o resíduo de lixadeira de algodão, proveniente do beneficiamento da fibra de algodão nas indústrias têxteis. Esse resíduo de algodão foi cedido pela Indústria Santanense, situada em Itaúna/MG. A serragem de eucalipto utilizada nas formulações de alguns tratamentos e aquele que serviu como testemunha foram obtidos obtida junto ao Departamento de Ciências Florestais da UFLA. O farelo de trigo foi utilizado como suplemento para os substratos, uma vez que tradicionalmente se utiliza serragem ou outro resíduo lignocelulósico suplementado com algum tipo de farelo.

Para a formulação dos substratos, foram feitas as pesagens, conforme o percentual de cada matéria-prima considerando seu teor de nitrogênio em matéria-seca, de forma que os substratos ficassem na faixa de $0,5 \%$ a $1,0 \%$ de $\mathrm{N}$-total com base na matéria seca dos materiais utilizados. Os tratamentos foram realizados da seguinte maneira: $\mathrm{T}_{1}$ $80 \%$ de serragem $+20 \%$ de farelo (testemunha) $\mathrm{T}_{2}-50 \%$ de resíduo $+50 \%$ de serragem; $\mathrm{T}_{3}-45 \%$ de resíduo $+45 \%$ serragem $+10 \%$ de farelo; $\mathrm{T}_{4}-40 \%$ de resíduo $+40 \%$ serragem $+20 \%$ de farelo e $\mathrm{T}_{5}-80 \%$ de resíduo $+20 \%$ de farelo.

Para o preparo dos substratos, as matérias-primas foram misturadas em tambores de fibra com capacidade para $100 \mathrm{~L}$, adicionando-se água até o ponto que ocorre um leve escorrimento entre os dedos quando pressionados, indicando que a umidade estaria na faixa de $60 \%$ a $70 \%$. Para o posterior cálculo da eficiência biológica, a umidade real de cada tratamento foi determinada, obtendose amostras compostas de cada substrato, as quais foram submetidas a secagem em estufa a $65^{\circ} \mathrm{C}$ até obtenção de peso constante. Dessa forma foi determinada a massa seca do substrato em porcentagem para efeito de cálculo da eficiência biológica. Para as análises de proteína, FDN e FDA, a matéria seca ainda foi corrigida, após secagem das amostras a $105^{\circ} \mathrm{C}$.

Para cada tratamento, foram utilizadas 10 repetições (cada saco plástico com $2 \mathrm{~kg}$ de substrato umedecido), portanto, 50 parcelas, que foram autoclavadas a $121^{\circ} \mathrm{C}$ a 1 
atm de pressão por duas horas, sendo o processo repetido, com um intervalo de 24 horas entre a primeira e a segunda autoclavagem. Após o resfriamento, os substratos foram inoculados na proporção de $1 \%$, ou seja, $20 \mathrm{~g}$ de inoculante por $2 \mathrm{~kg}$ de substrato. A inoculação ocorreu em câmara de fluxo laminar para evitar a contaminação do material autoclavado. Os substratos foram vedados com papel filtro preso a um aro de cano PVC por meio de elástico, permitindo assim a troca gasosa do fungo e evitando a contaminação por fungos competidores. As parcelas foram dispostas aleatoriamente na casa de colonização, onde ficaram por um período de 20 a 60 dias a temperatura ambiente, até que todos os tratamentos, ficassem completamente colonizados. Após a colonização de todos os tratamentos foram realizados vários cortes nos sacos plásticos, para que pudessem ser umedecidos. Após o umedecimento dos substratos na casa de cultivo, a umidade foi controlada por meio de nebulização, para que o ambiente ficasse com a umidade entre $80 \%$ e $90 \%$. A temperatura da casa de cultivo foi monitorada por meio de um termômetro de máxima e mínima, que registrou temperaturas entre $14^{\circ} \mathrm{C}$ a $31^{\circ} \mathrm{C}$, durante o cultivo.

Durante quarenta e cinco dias, ocorreram as colheitas, tendo quatro fluxos de cogumelos, neste período, que serviu de base para avaliação estatística da produtividade e EB. Os cogumelos eram colhidos, pesados e desidratados, mas antes da pesagem era feita a limpeza dos resíduos de substratos que ficavam ligados à base do estipe.

A produtividade foi calculada em $\mathrm{g}$ de cogumelos frescos / g substrato úmido, multiplicado por 100 , e a eficiência biológica (EB) em g de cogumelos frescos / g de substrato seco, multiplicado por 100.

Os teores de nitrogênio-total (N-total) das matériasprimas e dos substratos (tratamentos) em diferentes etapas de produção foram determinados por meio do método de Kjeldahl (AOAC, 1990), e os teores de FDN (Fibra Detergente Neutra), FDA (Fibra Detergente Ácida), celulose, hemicelulose e lignina definidos de acordo com a metodologia proposta por Van Soest, descrito por Silva \& Queiroz (2002). Todas essas análises foram realizadas no Laboratório de Nutrição Animal do Departamento de Zootecnia da UFLA.

O arranjo experimental no cultivo dos cogumelos foi realizado por meio de DIC - delineamento inteiramente casualizado. Para análise estatística, usou-se o SISVARUFLA, e as médias foram separadas por meio do teste de Scott-knott a $5 \%$ de probabilidade para produtividade e eficiência biológica (EB).

\section{RESULTADOS E DISCUSSÃO}

Na Tabela 1, pode-se observar os valores encontrados para matéria seca (MS), proteína bruta (PB), fibra em detergente neutro (FDN), fibra em detergente ácido (FDA), celulose (Cel), hemicelulose ( $\mathrm{H}-\mathrm{Cel})$ e lignina em porcentagem dos diferentes substratos, em diferentes estágios de produção, no cultivo de Pleurotus sajor- caju.

Entre os substratos testados, antes do início do cultivo, os valores para celulose ficaram entre $40,06 \%$ e $58,15 \%$; para hemicelulose os teores variaram entre $8,70 \%$ e $15,59 \%$; e os resultados encontrados para lignina tiveram variação entre $18,05 \%$ e $30,47 \%$ (Tabela 1). Em todos os tratamentos, observou-se menor teor de MS em relação ao peso úmido de cada substrato após os processos de colonização e produção dos cogumelos. Em relação à $\mathrm{PB}$ pode-se observar em todos os substratos que houve aumento durante o cultivo do Pleurotus, possivelmente relacionado à produção de proteína microbiana, durante o processo de crescimento micelial, na colonização do substrato.

Em relação à fibra, pode-se observar (Tabela 1) que houve diminuição da FDN durante os processos de colonização dos substratos e produção dos cogumelos, enquanto que para FDA não se observou a mesma tendência, com exceção do substrato 1 que apresentou diminuição durante o cultivo do cogumelo. A celulose aumentou em todos os tratamentos em relação aos substratos iniciais e o substrato pós-cultivo, enquanto que a hemicelulose e a lignina diminuíram em todos os tratamentos com os estágios de produção do Pleurotus sajor-caju. A diminuição expressiva da lignina esta relacionada com a eficiência destes fungos em degradar esta estrutura e em alguns casos preferencialmente à celulose e a hemicelulose, como foi observado no experimento. Considerando que o teor de celulose é calculado em função do teor de fibra total, pode-se inferir que a degradação de lignina e hemicelulose foi mais expressiva, resultando numa maior concentração relativa de celulose. Schmidt et al. (2003) relataram que os fungos basidiomicetos degradam preferencialmente a lignina, sem provocar perdas consideráveis de celulose e hemicelulose. Platt et al. (1981) afirmaram que 40 a $50 \%$ do conteúdo de lignina pode ser diminuído num período de 35 a 45 dias, cultivando Pleurotus sobre palha de arroz. No presente trabalho, a degradação preferencial de lignina foi também observada, mas, além disso, verificou-se também uma degradação expressiva de hemicelulose em alguns tratamentos, ao contrário do que foi relatado por Schmidt et al. (2003). 
Tabela 1 - Teores de matéria seca (MS), proteína bruta (PB), fibra em detergente neutro (FDN), fibra em detergente ácido (FDA), celulose (Cel), hemicelulose (H-Cel) e lignina em porcentagem dos diferentes substratos, em diferentes estágios de produção, no cultivo de Pleurotus sajor- caju.

\begin{tabular}{lccccccc}
\hline Tratamentos & MS & PB & FDN & FDA & Cel & H-Cel & Lig \\
\cline { 2 - 7 } & \multicolumn{7}{c}{ Fig } \\
\hline Substrato 1 I & 96,10 & 4,23 & 87,23 & 72,54 & 40,06 & 14,70 & 30,47 \\
Substrato 1 C & 93,43 & 4,86 & 88,51 & 66,89 & 44,12 & 21,61 & 21,21 \\
Substrato 1 P & 92,60 & 5,13 & 72,49 & 61,36 & 41,90 & 11,13 & 17,34 \\
Substrato 2 I & 98,02 & 2,42 & 90,33 & 81,63 & 58,15 & 8,70 & 22,70 \\
Substrato 2 C & 94,84 & 2,71 & 91,39 & 82,18 & 67,03 & 6,21 & 13,44 \\
Substrato 2 P & 92,65 & 2,83 & 88,34 & 82,30 & 71,73 & 6,05 & 9,39 \\
Substrato 3 I & 98,51 & 2,82 & 93,47 & 77,88 & 58,00 & 15,59 & 18,24 \\
Substrato 3 C & 93,37 & 3,38 & 90,61 & 79,52 & 65,10 & 10,09 & 13,21 \\
Substrato 3 P & 93,36 & 3,26 & 84,53 & 78,75 & 68,59 & 5,78 & 8,54 \\
Substrato 4 I & 96,55 & 4,11 & 87,86 & 76,02 & 57,15 & 11,84 & 18,05 \\
Substrato 4 C & 92,68 & 4,77 & 90,25 & 82,49 & 66,35 & 7,76 & 13,76 \\
Substrato 4 P & 93,47 & 4,92 & 78,15 & 74,25 & 61,92 & 3,90 & 10,78 \\
Substrato 5 I & 95,12 & 4,13 & 89,65 & 76,76 & 57,55 & 12,89 & 18,21 \\
Substrato 5 C & 94,16 & 4,79 & 85,51 & 76,41 & 61,23 & 9,10 & 12,18 \\
Substrato 5 P & 94,08 & 4,98 & 81,01 & 75,93 & 61,57 & 5,08 & 8,80 \\
\hline
\end{tabular}

$\mathrm{I}^{1}=$ substrato inicial, antes da autoclavagem; $\mathrm{C}^{2}=$ substrato colonizado, antes da indução; $\mathrm{P}^{3}=$ substrato após a produção e colheita dos cogumelos.

Conforme pode ser observado na tabela 1 , a degradação de hemicelulose, no tratamento 5 , foi muito maior do que aquela observada no tratamento 1 . Considerando que os dois tratamentos possuíam a mesma concentração de farelo de trigo, esses resultados sugerem ou uma diferença na qualidade entre a hemicelulose presente na serragem e aquela presente no resíduo de algodão, ou que a serragem possui outros compostos que podem ter limitado a degradação da sua hemicelulose. Segundo Castro et al. (2004), o Pleurotus sajor-caju, mostrou-se eficiente em reduzir as frações FDN e FDA e em aumentar o teor de proteína bruta dos substratos à base de resíduo de algodão no cultivo desse fungo, atribuindo as alterações na fibra como sendo o resultado do metabolismo do fungo $P$. sajor-caju, que é capaz de solubilizar parte dos componentes da parede celular do resíduo.

As alterações promovidas nos substratos durante este experimento (Tabela 1), também foram observadas por Bisaria et al. (1997), que trabalharam com Pleurotus sajorcaju inoculado em palhadas de arroz e trigo e observaram perda de matéria orgânica, indicando a degradação da celulose, hemicelulose e lignina do substrato e aumento na proteína bruta. Adamovic et al. (1998), em trabalho semelhante com Pleurotus ostreatus, observaram que parte substancial da MS da palhada foi degradada pelas enzimas do cogumelo.

Na Tabela 2, estão apresentados os dados de produtividade e de eficiência biológica do Pleurotus sajorcaju nos diferentes substratos. Os substratos testados foram estatisticamente diferentes entre si, para produtividade e eficiência biológica, pelo teste de ScottKnott a 5\% de probabilidade.

Em relação a produtividade, o $\mathrm{T}_{5}(80 \%$ resíduo de lixadeira $+20 \%$ farelo de trigo) foi o que obteve a melhor resultado com 22,46\% (Tabela 2). As formulações dos substratos de $\mathrm{T}_{4}$ e $\mathrm{T}_{1}$ foram os que apresentaram o segundo e o terceiro melhor resultado de produtividade com $17,22 \%$ e $13,64 \%$, respectivamente (Tabela 2). $\mathrm{O} \mathrm{T}_{2}$, apesar de ter permitido a colonização do substrato, não apresentou produção de cogumelos, indicando que a suplementação do substrato com o farelo de trigo foi essencial para a frutificação. A eficiência biológica (EB) do $\mathrm{T}_{5}(80 \%$ resíduo de lixadeira $+20 \%$ farelo de trigo) foi de $71,48 \%$, valor este bastante superior $(\mathrm{P}<0,05)$ aos demais tratamentos. Os tratamentos $\mathrm{T}_{4}, \mathrm{~T}_{1}$ e $\mathrm{T}_{3}$ apresentaram valores menores $(\mathrm{P}<0,05)$, decrescendo nesta ordem, em relação a eficiência biológica (Tabela 2). 
Tabela 2 - Avaliação da produtividade e eficiência biológica (EB) dos diferentes substratos para cultivo de Pleurotus sajor-caju.

\begin{tabular}{ccc}
\hline Tratamentos & $\begin{array}{c}\text { Produtividade } \\
(\%)^{*}\end{array}$ & $\begin{array}{c}\text { Eficiência Biológica } \\
\text { EB }(\%)^{* *}\end{array}$ \\
\hline T1 & $13,64 \mathrm{c}^{+}$ & $43,26 \mathrm{c}$ \\
T2 & $0,00 \mathrm{e}$ & $0,00 \mathrm{e}$ \\
T3 & $11,49 \mathrm{~d}$ & $34,52 \mathrm{~d}$ \\
T4 & $17,22 \mathrm{~b}$ & $49,62 \mathrm{~b}$ \\
T5 & $22,46 \mathrm{a}$ & $71,48 \mathrm{a}$ \\
\hline
\end{tabular}

${ }^{+}$As médias seguidas da mesma letra na coluna não diferem estatisticamente entre si pelo teste Scott-Knott ao nível de 5\% de probabilidade.

$*$ Produtividade $=[(\mathrm{g}$ de cogumelos frescos $/ \mathrm{g}$ de substrato úmido $)$ $\mathrm{x}$ 100].

** Eficiência Biológica $(\mathrm{EB})=[(\mathrm{g}$ de cogumelos frescos $/ \mathrm{g}$ de substrato seco) x 100].

Nos três fluxos avaliados os quatro tratamentos produziram cogumelos em abundância e com boa aparência, com exceção do $\mathrm{T}_{2}$, que não produziu. $\mathrm{O}$ teor de $\mathrm{N}$ inicial no $\mathrm{T}_{2}$ foi o mais baixo com $0,39 \%$ e esse foi o tratamento que não teve inclusão de farelo de trigo, ingrediente protéico, em sua formulação. Bisaria et al. (1997), destaca a importância da suplementação protéica de substratos pobres em $\mathrm{N}$, na forma orgânica ou mineral, mas em pequenas quantidades, pois o excesso de $\mathrm{N}$ também pode inibir a síntese das enzimas degradadoras da lignina, podendo dessa forma, diminuir a degradabilidade do substrato e interferir negativamente na produção. No entanto, os resultados obtidos no presente trabalho não podem ser explicados apenas em função do teor de nitrogênio inicial, uma vez que o T3 também apresentou um teor de nitrogênio inicial relativamente baixo $(0,45 \%)$, porém, apresentou uma razoável produção de cogumelos, com produtividade acima de $10 \%$. Provavelmente, a suplementação com farelo de trigo foi importante por suprir a necessidade de vitaminas ou outros fatores de crescimento, como já foi demonstrado para diferentes espécies de basidiomicetos (Shin et al., 1997; Chang \& Miles, 2004).

A utilização de vários tipos de resíduos agrícolas disponíveis na região pode reduzir os custos da produção dos cogumelos do gênero Pleurotus. Dias et al. (2003) buscando novos substratos para cultivo de Pleurotus sajor-caju verificaram por meio do sistema axênico de cultivo que a palha de feijão pura apresentou $85,7 \%$ de $\mathrm{EB}$, enquanto que a palha de milho enriquecida com farelo de trigo teve $83,3 \%$.
Diferentes parâmetros podem ser utilizados para avaliar a produção de cogumelos, sendo a produtividade (peso fresco de cogumelos por peso úmido de substrato) e eficiência biológica (peso fresco de cogumelos por peso seco de substrato) os mais comuns (Chang \& Hayes, 1978). A apresentação dos resultados em produtividade é interessante, porque permite uma correlação direta entre a massa de cogumelos produzidos e a massa de substrato utilizada, mas conforme relatado por Chang \& Hayes (1978) a eficiência biológica (EB) permite uma comparação de produção de cogumelos entre diferentes tipos de substratos, uma vez que matérias-primas diferentes retêm água em diferentes proporções. Chang et al. (1981) produziram Pleurotus sajor-caju em resíduos da cultura de algodão, com EB de 79,18\%, em 4 fluxos produtivos. Royse \& Schisler (1987) obtiveram 85\% em EB para produção de Pleurotus ostreatus em palha de trigo e espiga de milho e $73 \%$ de EB para produção de $P$. sajor-caju no mesmo substrato e cultivo. Ragunathan \& Swaminathan (2003) trabalharam com P.sajor-caju em diferentes substratos lignocelulósicos e relataram uma eficiência biológica de 23,64 a 41,42\% para restos de colheita de algodão. Castro (2003) avaliou o uso de resíduo de lixadeira de algodão na produção de Pleurotus sajor-caju em substrato obtido por compostagem curta seguida de pasteurização e encontrou uma eficiência biológica de 55,73\%.

Dessa forma, podemos destacar que a eficiência biológica apresentada pelo $\mathrm{T}_{5}(71,49 \%)$, que foi aquele que apresentou a maior quantidade de resíduo de lixadeira de algodão (80\%) em sua formulação, apresenta-se próxima das melhores relatadas na literatura e superior ao relatado por Castro (2003). Esses resultados mostram o grande potencial de utilização desse resíduo para a produção do cogumelo $P$. sajor-caju e, provavelmente, de outras espécies de Pleurotus.

\section{CONCLUSÕES}

O resíduo de algodão suplementado com farelo de trigo mostrou ser um bom substrato para produção do cogumelo Pleurotus sajor-caju, fazendo uso da metodologia de cultivo axênico. O fungo promoveu alterações na estrutura da fibra e incremento de proteína nos substratos nas diferentes fases de produção, tornando-o mais apropriado para a alimentação animal. Portanto, o uso da tecnologia de cultivo de P. sajor-caju utilizando resíduo de lixadeira de algodão, é uma alternativa viável para condicionar este resíduo para outros usos, como alimentação de ruminantes, além da produção dos cogumelos, que são um alimento com alto valor nutritivo para o homem. 


\section{REFERÊNCIAS BIBLIOGRÁFICAS}

ADAMOVIC, M.; GRUBIC, G.; MILENKOVIC, I.; JAVONOVIC, R.; PROTIC, R.; SRETENOVIC, L.; STOICEVIC, L. The biodegradation of wheat straw by Pleurotus ostreatus mushrooms and its use in cattle feeding. Animal Feed Science Technology, Amsterdam, v.71, n.3/4, p.357-362, Apr. 1998.

ALMEIDA, O.C.; PAIVA, P.C.A.; REZENDE, C.A.P.; PEREZ, J.R.O.; BANYS, V.L.; MUNIZ, J.A.; BONFIM, M.A.; BONFIM, E.R.P. Cinética ruminal do resíduo têxtil da fibra do algodão submetido a tratamentos físicos e químicos. Ciência e Agrotecnogia,Lavras, v.26, n.4, p.846-851, jul./ago. 2002.

ASSOCIATION OF OFFICIAL AGRICULTURAL CHEMISTS. Official methods of the Associacion of Analytical Chemist. 15.ed. Washington, 1990. v.1, 684p.

BISARIA, R.; MADAN, M.; VASUDEVAN, P. Utilization of agro-residues as animal feed through bioconversion. Bioresource Technology, Oxford, v.59, n.1, p.5-8, 1997.

CAPELARI, M. Atividade biodegradadora e cultivo de três espécies comestíveis de basideomicetos: Pleurotus spp. e Agrocybe perfecta (Rick) sing. 1996. 190p. Tese (Doutorado em Botânica)-Universidade de São Paulo, São Paulo, 1996.

CASTRO, A.L.A. Resíduo de lixadeira do algodão: produção de cogumelo, ensilagem e alterações da composição bromatológica e degradabilidade. 2003. Dissertação (Mestrado em Zootecnia)-Universidade Federal de Lavras, Lavras, 2003.

CASTRO, A.L.A.; PAIVA, P.C.A.; DIAS, E.S.; SANTOS, J. Avaliação das alterações bromatológicas e de degradabilidade do resíduo de lixadeira do Algodão após tratamento biológico com Pleurotus sajor-caju. Ciência e Agrotecnologia, Lavras, v.28, n.3, p.608-613, maio/jun. 2004.

CHANG, S.T.; HAYES, W.A. The biology and cultivation of edible mushrooms. New York: Academic, 1978. 819p.

CHANG, S.T.; LAU, O.W.; CHO, K.Y. The cultivation and nutritional value of Pleurotus sajor-caju. European Journal of Applied Microbiology and Biotechnology, New York, v.12, n.1, p.58-62, 1981.

CHANG, S.T.; MILES, P.G. Mushrooms: cultivation, nutritional value, medicinal effect, and environmental impact. Boca Raton: CRC, 2004. 451p.
DIAS, E.S.; KOSHIKUMO, E.M.S.; SCHWAN, R.S.; SILVA, R. Cultivo do cogumelo Pleurotus sajor-caju em diferentes resíduos agrícolas. Ciência e Agrotecnologia, Lavras, v.27, n.6, p.1363-1369, nov./dez. 2003.

MANDEEL, Q.A.; AL-LAITH, A.A.; MOHAMED, S.A. Cultivation of oyster mushrooms (Pleurotus spp.) on various lignocellulosic wastes. World Journal of Microbiology \& Biotechnology, Oxford, v.21, p.601-607, 2005.

PLATT, M.; CHET, I.; HENIS, Y. Lignocellulose degradation during growth of the mushroom Pleurotus sp. Florida on cotton straw. European Journal of Applied Microbiology and Biotechnology, Oxford, v.13, n.2, p.194-201, 1981.

RAGUNATHAN, R.; SWAMINATHAN, K. Nutritional status of Pleurotus spp. grown on various agro-wastes. Food Chemistry, Oxford, v.80, n.3, p.371-375, Mar. 2003.

ROYSE, D.J.; SCHISLER, L.C. Yied and size of Pleurotus ostreatus and Pleurotus sajor-caju as effected by delayed-release nutriet. Applied Microbiology and Biotechnology, New York, v.26, n.2, p.191-194, May 1987.

SANTOS, J.; CASTRO, A.L.A.; PAIVA, P.C.A.; BANYS, V.L. Efeito dos tratamentos físicos e químicos no resíduo de lixadeira do algodão. Ciência e Agrotecnologia, Lavras, v.28, n.4, p.919-923, jul./ago. 2004.

SCHMIDT, P.; WECHSLER, F.S.; NASCIMENTO, J.S.; VARGAS JUNIOR, F.M. Tratamento do feno de braquiária pelo fungo Pleurotus ostreatus. Revista Brasileira de Zootecnia, Viçosa, v.32, n.6, p.1866-1871, nov./dez. 2003.

SHIN, G.G.; MEGURO, S.; KAWACHI, S. The active constituent in yeast extract for fruit body formation of Lentinula edodes. Canadian Journal of Microbiology, Ottawa, v.43, p.1202-1204, 1997.

SILVA, D.J.; QUEIROZ, A.C. Análise de alimentos: métodos químicos e biológicos. 3.ed. Viçosa, MG: UFV, 2002.

SOUZA, O. Tratamento de subprodutos e resíduos lignocelulósicos com uréia na alimentação de ruminantes. In: CONGRESSO NORDESTINO DE PRODUÇÃO ANIMAL, 1., 1998, Fortaleza. Anais... Fortaleza: Sociedade Nordestina de Produção Animal, 1998. p.195-213. 